\title{
Energy Consumption of Sugarcane and Corn Culture
}

\author{
Mauro D. Berni, Ivo L. Dorileo, and Paulo C. Manduca
}

\begin{abstract}
The present work aims to contribute with sustained economic expansion by studying strategies for expanding the energy supply in agribusiness. The characterization of specific energy consumption and energy indicators were performed considering a process of natural evolution, using logistic curves that describe the growth or evolution process. The specific energy consumption in agricultural activities was determined from data on the consumption of energy by machinery and equipments used in agricultural activities, as well as by establishing specific consumption indicators (ratio of energy consumed per unit produced) for each stage of production and by end-use. Two crops (corn and sugarcane) were evaluated. The technology levels reached by the Brazilian agricultural sector reflected on an increased productivity and competitiveness in the international market with improvement of machines and equipments efficiency and operational capacity. In sugarcane culture, for example, the productivity increased up to $50 \%$ from 2000 to 2014. It was also noticed a trend to reduce the use of low-power tractors and to increase the use of medium to high-power tractors, which has also favored the productivity increase. The incorporation of new technologies tends to be more intense in the crops that have an already established market. In Brazil, agricultural productivity in 2014 averaged 73 tonnes of sugarcane per hectare, according to figures from Brazil's Center for Sugarcane Technology (CTC). The percentage increase practically the same for the state of São Paulo, where productivity averaged 83.40 tonnes per hectare. In 1975, the average agricultural productivity was around 45 tons of sugarcane per hectare. In corn culture, according survey released by the National Food Supply Agency (CONAB), the national corn crop, produced in the 2014/15 summer growing season is estimated at $\mathbf{3 0 . 6 4}$ million tons. It represents a slight decline of $2.6 \%$ from the previous period, when the total volume 30.83 million tonnes. Productivity was up $4.7 \%$, soaring from 4,783 kilograms per hectare to 5,009 kilograms per hectare.
\end{abstract}

Index Terms - Corn, Sugarcane, energy indicators, specific energy consumption, energy indicators.

\section{INTRODUCTION}

The analysis of performance and trends of international markets shows that Brazil is a leader in the production and exportation of several products of the agricultural sector, as sugar and corn. Brazilian, due to the growing demand of Asian countries [1]. The Brazilian agricultural sector has been changing, mainly due to the modernization of the activities and to the expansion of the agricultural boundaries. Several government measures have stimulated such modernization, as the incentives granted to companies for the development of

Manuscript received May 9, 2016; revised December 21, 2016.

M. D. Berni and P. C. Manduca are with Interdisciplinary Center of Energy Planning, State University of Campinas, Brazil (e-mail: mberni@unicamp.br, mberni@unicamp.br).

I. L. Dorileo is with NIEPE, Federal University of Mato Grosso, Brazil (e-mail: ivo.leandrod@gmail.com). the Midwestern and Amazonian regions.

The agricultural sector is the basis that supports the whole agroindustrial complex, which includes industries of agricultural machinery, fertilizers and pesticides, and those that process the agricultural products into food and other manufactured goods. The agricultural sector also demands from the services sector, as dealers of agricultural machinery, stores that commercialize products for agriculture and technical assistance. It is estimated that the interrelation of products and services in the agricultural sector (agricultural and livestock) generates around $23 \%$ of the Brazilian Gross Domestic Product (GDP) and final energy consumption of the agricultural sector participates with $4.5 \%$ of the total energy consumed in Brazil in 2014 [2]. In 2014, in the energy matrix of the agricultural sector, $55.2 \%$ the consumption was from diesel oil, $23.9 \%$ from firewood, $20.5 \%$ from electricity and $0.4 \%$ from other sources, including charcoal, ethanol and wood wastes. On the other hand, besides being a consumer, the agricultural sector is also a self-producer of energy, which puts it into a different position when compared to other sectors.

Due to the strong international integration and to the need to remain economically competitive, the agricultural sector has invested in new technologies and has improved its business management. However, these investments have not immediately favored the energy use efficiency, even though the energy consumption per added value of the ratio has decreased from 99.9 tonnes of oil equivalent (toe)/103 US\$ GDP in 2009 to 93.1 toe/103 US\$ GDP in 2014 [3]. The areas that have been expanding are characterized by intensive use, with high levels of mechanization. There are some indicators of a steady expansion of the agricultural sector in medium and long terms: the better use of lands by sugarcane and corn crops. However, some barriers arise, as the lack of silos for grain storage, difficulties in logistics due to deficient transportation infrastructure, limitations of plantation because of the native forests preservation and ecological zoning, and the challenge of increasing the productivity of the crops, especially those destined to producing bioethanol, as sugarcane, so that it can become a commodity. If the Brazilian agricultural sector wants to continue its success full trajectory these challenges must be overcome, especially those related to increasing the agricultural production capacity, and to exploring the entire potential of human, technological, climate and natural resources.

The current technological status of the Brazilian agriculture is a result of the efforts of several actors: farmers, industry, researchers and politics. Efforts have been made to expand the offer of agricultural products. The modernization increased the agricultural productivity due to mechanization using tractors, combines and irrigation, and to the use of chemical inputs, as fertilizers and pesticides, in addition to the 
improvement of biological inputs. Besides the products offered, it is also necessary to improve the energy yield or efficiency (the energy consumption per unit of product), through the use of technological innovations. The incorporation and dissemination of these technologies, in the first moment (2002-2008), have increased the energy consumption from oil derivatives, which relatively decreased and stabilized from 2008 to 2014 around 10,500 toes. Last years the energy consumption matrix in the agricultural sector now points to a decrease in the use of firewood and increase in the use of electricity and decreased diesel oil (Fig. 1) [2].

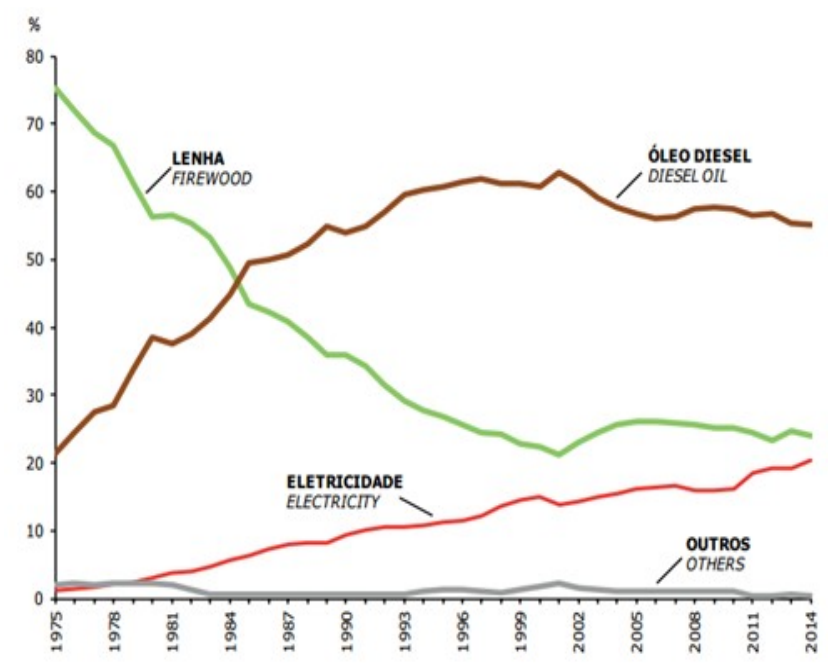

Fig. 1. Agricultural sector energy consumption.

As for the end-use distribution, the driving force is met by the consumption of diesel and electricity in agricultural machinery and implements run by internal combustion engines, and in industries that process the agricultural products into manufactured goods using electrical devices. The main activities include irrigation, soil preparation, grain drying, pesticide application, mechanical harvest, internal transportation, automatic milking, and refrigeration of products by mechanical systems.

\section{Methodology}

The study used data from sugarcane and corn crops of the agricultural sector in Brazil, provided by the Statistics Yearbooks of IBGE, in the years 1990, 2000 and 2010, were evaluated [3], [4], [5]. The data on energy consumption of the agricultural sector, in the period studied, was extracted from the Brazilian National Energy Balance [2].

The coefficients for accounting the energy used in the productive system, for several activities, were determined based on literature data.

Methodologies have been developed to study the energy yields in terms of energy produced (outputs) and consumed (inputs) in a system, both at the micro level, represented by a single activity, and at the macro level for an entire sector of the economy.

From the relationship between outputs and inputs converted into energy units or equivalents (joule, calorie or toe), it can be obtained an indicator that points to how many units of energy are consumed for each resulting unit of the productive system under evaluation.

The search for a common indicator that allows comparing systems implies the hypothesis that it is possible to convert the different productive processes to a single energy unit. Therefore, data of the physical production of crops were transformed from quantities in tonnes to tonnes of oil equivalent (toe). This work used two criteria were established to crops to be evaluated: i) the macroeconomic criteria, which included the large scale production; and ii) the criterion of energy consumption.

\section{A. Energy Consumption by Crop}

The characterization of the energy consumption was performed for each crops production. The production and irrigation systems and the machinery used in each system were described for existent production systems within a standard system, which best characterized the production of the Brazilian agricultural sector for each crop. The standard production system was composed by the stages: I) soil and seed preparing, and planting; II) crop treating; III) irrigation; IV) harvest; V) internal transportation; VI) storage; and VII) processing. The data evaluated for each Brazilian region (North, Northeast, Middle West, Southwest, and South) were: planted area (ha), harvested area (ha), amount produced (ton), value of the production (Brazilian money, $\mathrm{R} \$$ ) and the mean productivity ( $\mathrm{kg} / \mathrm{ha})$.

The land use definitions adopted by [5] were used: i) permanent culture: includes area planted or under preparation for planting long-term crops. SIDRA/IBGE does not consider sugarcane and corn permanent crops, even though they are long-term crops; and ii) temporary culture: includes area planted or under preparation for planting short-term crops, usually less than one year-long, and that only produce once, since the plant is destroyed in the harvest.

\section{SPECIFIC ENERGY CONSUMPTION (SEC) IN AGRICULTURAL SECTOR}

The machinery and equipment considered were the ones identified to be the most representative contributors to the SEC of each production system.

\section{A. SEC of Diesel Internal Combustion Engines of Tractors and Combines}

Considering the machines do not operate $100 \%$ of the time at full power, ranges of power were considered, with their respective mean uses of power and time [6].

Mean power used and diesel consumed were used to calculate the mean SEC per hour for each piece of machinery. The mean power used was from 33.8 to $65.6 \mathrm{HP}$ for tractors and from 62.4 to $83.2 \mathrm{HP}$ for combines.

The diesel consumption varied between 7.03 and $13.62 \mathrm{~L} / \mathrm{h}$ for tractors and between 12.98 and $17.30 \mathrm{~L} / \mathrm{h}$ for combines [7]. The SEC value of diesel internal combustion engines was obtained from the mean diesel consumption per power unit, and was determined as $0.2078 \mathrm{~L} / \mathrm{HP}-\mathrm{h}$ [8]. This SEC value was assumed as standard for each crop.

\section{B. SEC of Diesel Internal Combustion Engines of Trucks}

The mean SEC of trucks used in the internal transportation 
was calculated for maximum and minimum consumption, considering mean velocity of $30 \mathrm{~km} / \mathrm{h}$ (Marques et al., 2009), and was determined as $6.45 \mathrm{~L} / \mathrm{h}$. The mean number of hours the truck is used [7] was used to determine the real SEC per crop.

\section{SEC of Irrigation by Center Pivot}

The SEC of electric engines used in irrigation equipments was determined as $0.93 \mathrm{HP} / \mathrm{ha}$, based on the energy consumption [9] and the mean time of equipment use [7].

This value was used for irrigation of sugarcane. It was assumed that the participation of irrigated areas of corn was $19 \%$ [10].

\section{SEC of Lighting and Other Electricity Uses}

The SEC of lighting and other electricity uses followed the same calculation procedure for two crops considering the electricity used per hectare [7]. The SEC found was equally divided among the seven stages of production considered in this work, since it was considered that all steps consume electricity.

\section{E. Specific Energy Consumption Calculation}

The energy consumption indicators were evaluated crossing the information for each of the two crops. Changes in energy efficiency can be measured by evaluating energy use by unit of activity (ton, hectare). SEC was calculated for a specific crop "i”" to process one unit (ton, ha), as:

$$
\mathrm{SEC} i=\mathrm{E} i / \mathrm{P} i
$$

Where SECi is the energy intensity indicator, based on the physical production (e.g. GJ/ton); $\mathrm{E} i$ is the energy consumption of the crop " $i$ "; and Pi is the production of the crop (ton, ha).

\section{ENERGY CONSUMPTION BY END-USE}

The main crops of Brazil have expanded strongly since 1996, using lands of regions favorable to grow sugarcane and corn. Specifically sugarcane crops also had to overcome the limitations of preserving indigenous forests and ecological zoning.

The end-use of the energy in the agricultural sector in Brazil was estimated. The main participation on the total energy consumption by source was from diesel, electricity, and firewood.

The participation on the total energy consumption by energy type was divided in driving force (DF), lighting (Li), other uses $(\mathrm{OU})$, direct heating $(\mathrm{DH})$, process heat $(\mathrm{PH})$, cooling $(\mathrm{C})$ and air conditioning (AC).

The total energy consumption of the agricultural sector was estimated from the SEC calculated and the total acreage area, total agricultural production.

The evaluations were performed crossing information from the SIDRA system (IBGE System of Automatic Recovery) for temporary cultures in Brazil.

In the agricultural subsector the end-use that contributed the most to the total energy consumption was $\mathrm{DH}+\mathrm{PH}(50.45$ $\%$ ), followed by DF (44.77\%), Li + OU (4.78\%), and C + AC
$(0.00 \%)$.

As for the energy source demanded, firewood contributed with $50.2 \%$, diesel with $44.7 \%$, electricity with $4.8 \%$, and other resources, as LPG and charcoal, with $0.2 \%$. In the participation of each stage, processing (stage VII) accounted for $51.14 \%$ of energy consumption, followed by soil preparing and planting (stage I) with $17.34 \%$, crop treating (stage II) with $14.58 \%$, harvest (stage IV) with $8.77 \%$, irrigation (stage III) with $3.76 \%$, internal transportation (stage V) with $3.64 \%$, and storage (stage VI) with $0.79 \%$.

\section{A. SEC in Sugarcane Crop}

In 2009 the area planted with sugarcane in Brazil was 8.8 million ha; the Southeastern region was responsible by two thirds of it, and also presented the highest productivity $(83,777 \mathrm{~kg} / \mathrm{ha})$.

The Northeastern region presented the second largest planted area with the lowest productivity $(58,266 \mathrm{~kg} / \mathrm{ha})$.

The difference in productivity is due to different incorporation of technology in these regions, but there was a general tendency to increase the planted area by a larger factor than the productivity [3].

The main pieces of machinery used in sugarcane crop were: farm tractor $105 \mathrm{HP}$ for $30 \times 32$ " harrow; farm tractor $120 \mathrm{HP}$ $4 \times 4$ for contour plough $20 \times 26$ ", leveling harrow $52 \times 22$ ", 2-row fertilizer, subsoiler, and cultivator; farm tractor $4 \times 2$ $65 \mathrm{HP}$ for lime distributor $2.3 \mathrm{~m} 3$; farm tractor $4 \times 275 \mathrm{HP}$ for cultivator, field braker, and windrower; farm tractor 90 HP $4 \times 4$ for spray bar $18 \mathrm{~m}$; farm tractor $4 \times 475 \mathrm{HP}$ for grader blade, and filter cake distributor; backhoe $120 \mathrm{HP}$; farm tractor $75 \mathrm{HP}$ for 2-row hedger; hydro roll $160 \mathrm{HP}$; trucks; boiler, oven, and furnace; luminaires; and others [7].

The total SEC of sugarcane crop was $0.0491 \mathrm{GJ} /$ ton. The main energy end-uses were DF (71.0\%), DH + PH (14.9\%), and $\mathrm{Li}+\mathrm{OU}(14.1 \%)$. Diesel contributed with $71.0 \%$, firewood with $14.9 \%$, and electricity with $14.1 \%$.

\section{B. SEC in Corn Crop}

In 2009 the area planted with corn in Brazil was 14.1 billion ha. The Southeastern region presented the highest productivity $(4,935 \mathrm{~kg} / \mathrm{ha})$, while the Northeastern region produced only $1,658 \mathrm{~kg} / \mathrm{ha}[3]$.

The difference is due to technology incorporation, i.e., mechanical harvest and new technologies in cultivation, which shows the potential for improvement.

The main producing states in Brazil were Paraná and Mato Grosso, which, together, accounted for $35.9 \%$ of the national production [10].

The main pieces of machinery used in corn crop were: farm tractor $4 \times 265 \mathrm{HP}$ for lime distributor $2.3 \mathrm{~m} 3$, cultivator/fertilizer, and spray bar $18 \mathrm{~m} / 2,000 \mathrm{~L}$; farm tractor $4 \times 4120 \mathrm{HP}$ for 10 -row planter, and dragging contour plough $20 \times 26$ "; seeds mixer; irrigation equipment (center pivot); combine $160 \mathrm{HP}$; trucks; boiler, oven, and furnace; luminaires; and others [7].

The total SEC of corn crop was $0.7863 \mathrm{GJ} /$ ton.

The main energy end-uses were DF (50.9\%), DH $+\mathrm{PH}$ (44.0\%), and $\mathrm{Li}+\mathrm{OU}$ (5.1\%). Diesel contributed with 50.9 $\%$, firewood with $43.8 \%$, and electricity with $0.2 \%$. 


\section{Main Conclusion This Section}

Sugarcane presented the lowest SEC (0.04911 GJ/ton).

Table 1 show SEC for nine crops in base year (2009) for Brazil.

TABLE I: AGRICULTURE SECTOR INDICATORS

\begin{tabular}{|c|c|c|}
\hline Crops & Total $(\mathrm{GJ} / \mathrm{ha})$ & Total $(\mathrm{GJ} / \mathrm{t})$ \\
\hline Cotton & 5.91 & 1.66 \\
\hline Rice & 7.80 & 1.79 \\
\hline Sugarcane & 3.84 & 0.04 \\
\hline Tobacco & 76.29 & 39.18 \\
\hline Orange & 11.32 & 0.51 \\
\hline Cassava & 31.39 & 2.30 \\
\hline Corn & 2.83 & 0.78 \\
\hline Soybean & 1.75 & 0.66 \\
\hline Wheat & 1.44 & 0.69 \\
\hline
\end{tabular}

Source: [4]

\section{TREnds AND Prospects of SEC FOR Agriculture SECTOR}

The trends were estimated considering a process of natural evolution, using logistic curves that describe the growth or evolution process, a long time, of any system, until it reaches a value at time " $t$ ". The evolution of SEC by end-use in the agricultural production was estimated for 20 years, departing from 2009 as base year. The logistic model that was determined for the whole Brazilian agricultural sector was:

$$
y=\frac{1}{\left(1+500 e^{(-0.5 t)}\right)}
$$

where $L=1$ is the asymptote; a is the SEC improvement rate with the use of efficient technology; $b$ is the trajectory of the improvement (transition interval gradient to the more efficient technology); and $t$ is the characteristic time that the improvement takes to go from the current state to the estimated state $(1,2,3 \ldots 20)$.

In the agriculture subsector, considering improvement rate of $10 \%$ for the whole agriculture sector, and a transition interval gradient of $100 \%$ (Fig. 2).

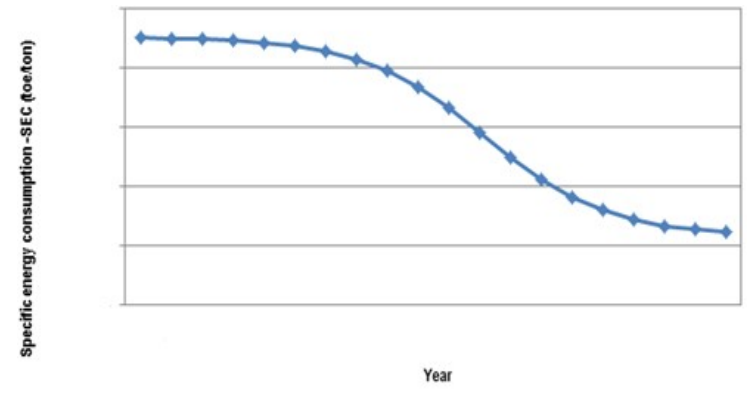

Fig. 2. Logistic curve: total SEC reduction for sector.

With technology development during the next 20 years, the SEC in the agriculture sector is estimated to decrease from 0.067 toe/ton to around 0.0061 toe/ton. The Brazilian agricultural sector have reflected on increased productivity and competitiveness in the international market. The improvement of machines and equipments efficiency and operational capacity was fundamental to achieve such state. For sugarcane, for instance, the productivity increased up to
$60 \%$ from 1975 to 2014 according survey released by the National Food Supply Agency (CONAB). It has also been noticed a trend to reduce the use of low-power tractors and to increase the use of medium to high-power tractors, which has also favored the productivity increase.

One promising technological perspective for the whole Brazilian agricultural sector is intensifying the GPS and precision agriculture systems with the Variable-Rate Technology (VRT). These are specialized controls that vary the amount of material deposited, the concentration of the input, or the proportion between different materials. The mechanization and irrigation increases the productivity, and despite consuming more total energy, it decreases the SEC due to increased productivity. On the other hand, expanding the irrigation system in Brazil depends on introducing equipments and overcoming management barriers. The production factors must be at optimum level so that the irrigation system can be at maximum production face to the investment needed and resources consumed, aiming to achieve mean efficiency of $38.0 \%$ of water use, which is the current world standard [11]. Biotechnology is one of the most important tools today to improve the productivity and to minimize the SEC.

The incorporation of new technologies tends to be more intense in the crops that have an already established market and need to maintain and expand their market share, as the meat chain, and in those that aim to gain markets, as sugarcane and ethanol. In these cases, the productivity increase is a priority to optimize energy consumption, both by decreasing the SEC for crops and by reusing residues to generate more energy from waste biomass [11].

\section{FINAL CONSIDERATIONS}

The technology levels reached by the Brazilian agricultural sector have reflected on increased productivity and competitiveness in the international market with improvement of machines and equipment efficiency and operational capacity. In sugarcane culture, for example, the productivity increased up to $60 \%$ from 1975 to 2014 . It has also been noticed a trend to reduce the use of low-power tractors and to increase the use of medium to high-power tractors, which has also favored the productivity increase. The incorporation of new technologies tends to be more intense in the crops that have an already established market.

\section{ACKNOWLEDGEMENTS}

The authors thank the Interdisciplinary Centre of Energy Planning (NIPE/UNICAMP) for supporting structure to this greatly acknowledged work.

\section{REFERENCES}

[1] MAPA, Projeções do Agronegócio 2010/2011 a 2020/2021, Ministério da Agricultura, Pecuária e Abastecimento, 2011, p. 59.

[2] EPE, Empresa Brasileira de Pesquisa Energética, Balanço Energético Nacional - Ano base 2014, Ministério de Minas e Energia, 2015 , p. 155 .

[3] D. Connolly, H. Lund, B. V. Mathiesen, and M. Leahy, "A review of computer tools for analyzing the integration of renewable energy into various energy systems," Applied Energy, vol. 87, pp. 1059-1082, 2010 
[4] F. B. Torres, C. F. Albejante, M. D. Berni, and I. L. Dorileo, "Síntese de informações resultados de experiência profissional pretérita, contatos profissionais, e levantamento de dados junto às instituições privadas e estatais," Relatório Final. Ed. Empresa de Pesquisa Energética (EPE) e Empresa MCPAR Engenharia, 2011, p. 616.

[5] SIDRA/IBGE. Sistema IBGE de Recuperação Automática. Banco de dados Agregados, Instituto Brasileiro de Geografia e Estatística (IBGE). [Online].

Available: http://www.ibge.gov.br/home/estatistica/indicadores/precos/sinapi/di vulgacao.shtm

[6] J. S. Kamphorst and J. Deere, Quanto Gasta seu Trator, Revista Cultivar Máquinas, 2003, pp. 8-12.

[7] Agrianual, Anuário da Agricultura Brasileira, Ed. FNP-Consultoria e Comércio, São Paulo-Brazil, p. 482, 2010.

[8] J. G. Watson, "Characterization of Off-Road Diesel Emissions of Criteria Pollutants," Final Report, WP-1336, Strategic Environmental Research and Development Program, p. 209, 2008.

[9] P. A. Marques, M. A. Fonseca, and P. V. Baldotto, "Influence of lettuce as cover crop of the soil on sprinkler irrigation uniformity and parameters of efficiency," Horticultura Brasileira, vol. 27, pp. 377-382, 2009
[10] Embrapa. (2010). Cultivo do Milho 2010. Empresa Brasileira Pesquisa Agropecuária. [Online]. Available: http://sistemasdeproducao.cnptia.EMBRAPA.br/FontesHTML/Milho /CultivodoMilho_6ed/index.htm

[11] T. Forster-Carneiro, M. D. Berni, I. L. Dorileo, and M. A. Rostagno, "Biorefinery study of availability of agriculture residues and wastes for integrated biorefineries in Brazil," Resources, Conservation and Recycling, vol. 77, pp. 78-88, 2013.

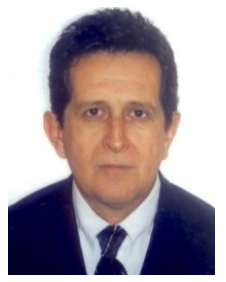

M. D. Berni was born in 1958, in São Paulo, SP Brazil. He received his BSc degree in Production Engineering, from UFSCAR in 1983, MSc degree in Energy System, from UNICAMP in 1992, PhD degree in Energy and Environment, from UNICAMP in 1998. Since 2005, he has been a researcher at UNICAMP State University of Campinas at the Interdisciplinary Center for Energy Planning (NIPE). From 1984 to 2004, he had worked as a Process Engineer of pulp and paper, forests, sugarcane and beverage industries. 

Power Systems and Energy Management 
